\title{
Dietary fish oil augments nitric oxide production or release in patients with Type $\mathbf{2}$ (non-insulin-dependent) diabetes mellitus
}

\author{
G. E.McVeigh ${ }^{1}$, G.M. Brennan ${ }^{1}$, G.D.Johnston ${ }^{1}$, B.J.McDermott ${ }^{1}$, L.T.McGrath ${ }^{1}$, W. R.Henry ${ }^{2}$, J.W. Andrews ${ }^{3}$ \\ and J. R.Hayes ${ }^{2}$ \\ ${ }^{1}$ Department of Therapeutics and Pharmacology, The Queen's University of Belfast, \\ ${ }^{2}$ Department of Medicine, Belfast City Hospital and ${ }^{3}$ Department of Medicine, Whiteabbey Hospital, Belfast, Northern Ireland
}

\begin{abstract}
Summary. Decreased release of nitric oxide from damaged endothelium is responsible for the impaired endothelium-dependent vasodilator responses found in animal models of vascular disease. Dietary supplementation with fish oils has been shown to augment endothelium-dependent relaxations, principally by improving the release of nitric oxide from injured endothelium. Using forearm venous occlusion plethysmography we studied vascular responses to $60,120,180$ and $240 \mathrm{nmol} / \mathrm{min}$ of acetylcholine (an endothelium-dependent vasodilator) and 3,6 and $9 \mathrm{nmol} / \mathrm{min}$ of glyceryl trinitrate (an endothelium-independent vasodilator) infused into the brachial artery in 23 patients with Type 2 (non-insulin-dependent) diabetes mellitus. $\mathrm{N}^{\mathrm{G}}$ monomethyl-L-arginine was employed to inhibit stimulated and basal release of nitric oxide from the endothelium. On completion of the baseline studies patients randomly received either fish oil or matching olive oil capsules in a double-blind crossover fashion for 6 weeks followed by a 6 -week washout period and a final 6 -week treatment phase. Studies, identical to the initial baseline studies, were performed at the end of the active treatment periods at 6 and 18 weeks. Fish oil supplementation signifi-
\end{abstract}

cantly improved forearm blood flow responses to each dose of acetylcholine when compared to the vasodilator responses recorded at baseline and after olive oil administration $(p<0.01)$. Neither fish oil nor olive oil supplementation produced any significant changes in forearm blood flow to the incremental infusions of glyceryl trinitrate when compared with responses recorded during the baseline studies. $\mathrm{N}^{\mathrm{G}}$ monomethyl-L-arginine significantly reduced forearm blood flow from maximal stimulated values to acetylcholine when compared to the uninhibited decline in flow to acetylcholine infusions at comparable time points $(p<0.01)$. Treatment with fish oils improved endothelium-dependent responses to acetylcholine without altering endothelium-independent responses to glyceryl trinitrate. By increasing stimulated nitric oxide release from the endothelium fish oils may afford protection against vasospasm and thrombosis in patients with diabetes mellitus.

Key words: Acetylcholine, $\mathrm{N}^{\mathrm{G}}$ monomethyl-L-arginine, nitric oxide, glyceryl trinitrate, fish oils, Type 2 (non-insulin-dependent) diabetes mellitus.
Patients with diabetes mellitus have an increased cardiovascular morbidity and mortality compared with the general population [1]. The development of diabetic vascular complications is a multifactorial process where altered lipoproteins, hyperinsulinaemia, hypertension and changes in blood rheology act in concert with hyperglycaemia to promote endothelial injury and accelerate the atherosclerotic process [2]. Thus, therapeutic advances leading to improved blood glucose control alone have proved disappointing in preventing the development and progression of macro- and microvascular complications associated with the disease [3].

Omega- 3 fatty acids are known to favourably influence many of the mechanisms involved in atherogenesis [4] and appear to reduce mortality from coronary heart disease $[5$, $6]$ and may therefore have therapeutic potential in pre- venting complications associated with diabetes mellitus. Recent evidence suggests dietary fish oils rich in eicosapentaenoic (20:5) and docosahexaenoic (22:6) fatty acids may prevent or delay diabetic complications attributable to microvascular disease [7]. While omega-3 fatty acids are recognised for their antiplatelet actions and effects on lipoprotein metabolism, there is increasing evidence that their vascular protective actions are expressed at the level of the vessel wall after incorporation into the phospholipids of cell membranes [8]. Dietary fish oil supplementation has been shown to improve endotheliumdependent relaxations to pharmacological stimulation in atherosclerotic porcine [9] and human [10] coronary vasculature. These improved vasodilator responses are mediated principally through the increased release of endothelium-derived relaxing factor $[11,12]$ now identified as 
Table 1. Fatty acid content of platelet membrane at baseline and after 6 weeks olive oil and fish oil supplementation

\begin{tabular}{llll}
\hline & Baseline & Fish oil & Olive oil \\
\hline Arachidonic acid & $23.2(22.1$ to 24.3$)$ & $20.2(19.3 \text { to } 21.1)^{\mathrm{a}}$ & $22.8 \pm(21.8$ to 23.8$)$ \\
Eicosapentaenoic acid & $1.2(0.2$ to 2.2$)$ & $2.9(2.2 \text { to } 3.6)^{\mathrm{b}}$ & $1.1(0.8$ to 1.4$)$ \\
Docosahexaenoic acid & $1.3(1.1$ to 1.5$)$ & $4.0(3.0 \text { to } 5.0)^{\mathrm{b}}$ & $1.6(0.9$ to 2.3$)$ \\
\hline
\end{tabular}

${ }^{a} p<0.01 ;{ }^{b} p<0.001$ vs baseline values. Data are expressed as mean and $95 \%$ confidence intervals. Arachidonic acid and the omega- 3 fatty acids eicosapentaenoic acid and docosahexaenoic acid expressed as percentage constituents of the platelet membrane lipid

nitric oxide (NO) [13] or an unstable nitroso compound related to NO [14]. Whether improved endotheliummediated responses would occur from damaged endothelium in diabetic patients ingesting fish oils is unknown.

This study was designed to investigate endotheliumdependent and independent responses to dietary fish oil and olive oil supplementation in the forearm vasculature of patients with Type 2 (non-insulin-dependent) diabetes.

\section{Patients and methods}

Twenty male and three female patients with Type 2 diabetes whose ages ranged from 45-61 years were recruited for study. Diabetic control was achieved by diet alone or diet plus sulphonylurea or biguanide preparations or both. Patients were excluded from study if there was a history of cerebrovascular disease, ischaemic heart disease, or peripheral vascular disease, hypertension (blood pressure $>150 / 90$ ), significant renal impairment (creatinine clearance $<30 \mathrm{ml} / \mathrm{min}$ ) or if they were taking cardiovascular drugs. All patients underwent an extensive array of tests including retinal photography, ankle/arm Doppler ratios, cardiac autonomic function tests, biothesiometer measurements of vibration perception and urine collections for microalbuminuria and overt proteinuria as previously described, prior to entry into the study [15]. All participants gave written informed consent for all procedures. This study was approved by the local ethical committee of The Queen's University of Belfast.

\section{Study design}

Patients entered a double-blind placebo controlled study with random allocation of treatments consisting of three 6-week phases. During the first 6 weeks the patients received 10 capsules per day of fish oil (Maxepa; Duncan Flockhart, Greenford, Middlesex, UK) or identical appearing olive oil placebo capsules (preparations kindly provided by Duncan Flockhart) in a random fashion. Following a 6 week washout period, patients were allocated the capsules they had not previously received during the initial treatment phase for a final 6-week period. A 6-week treatment phase permitted sufficient time for incorporation of the fatty acids into the cell membranes. Fish oil capsules contained $18 \%$ weight/weight eicosapentaenoic acid and $12 \%$ docosahexaenoic acid to provide a daily intake of $1.8 \mathrm{~g}$ of eicosapentaenoic acid and $1.2 \mathrm{~g}$ of docosahexaemoic acid. The vitamin $\mathrm{A}$ content was less than $100 \mathrm{IU} / \mathrm{g}$ and the vitamin D content less than $10 \mathrm{IU} / \mathrm{g}$. Patients adhered to their regular diets and medications throughout the study periods. Compliance with the medication was assessed by capsule counts on return of the bottle containers and by measurement of platelet membrane fatty acid composition by gas chromatography.

\section{Protocol}

Forearm blood flow was measured bilaterally by venous occlusion plethysmography during the initial baseline studies and on completion of each of the active treatment periods. Drug infusions were performed in the experimental forearm to determine the direct effect of the vasoactive drugs, while measurements in the control arm were monitored to ensure systemic effects did not occur during this period. Acetylcholine chloride (Miochol; Coopervision, Southampton, UK) was used to assess endothelium-dependent vasodilation, $\mathrm{N}^{\mathrm{G}}$-monomethyl-L-arginine (L-NMMA), (Ultrafine Chemicals, Manchester, UK) was employed to inhibit basal and stimulated release of nitric oxide from the endothelium and glyceryl trinitrate (Nitrocine; Schwarz Pharma, Chesham, UK) was used as a smooth muscle vasodilator. A detailed description of the forearm blood flow and the vasoactive drug infusion protocols used during the initial baseline studies have been described previously [15] and were repeated in an identical fashion on completion of each active treatment period.

Venous blood was drawn from each subject after 30-min supine rest during the baseline study and on completion of the active treatment phases for estimation of glycated haemoglobin, fasting glucose and for measurement of platelet fatty acids. An uncuffed specimen was collected in EDTA tubes for estimation of the lipid and lipoprotein profiles by ultracentrifugation.

\section{Statistical analysis}

Forearm vasodilator responses to increasing doses of acetylcholine and glyceryl trinitrate in the diabetic subjects were analysed using the SPSS PC + package (SPSS Inc., Chicago, Ill., USA). Repeated measures analysis of variance was used to assess within-group and between-group responses for significant comparisons between doses. The relations between responses and baseline characteristics were examined using Dunnett's test. Comparisons between groups were assessed using paired $t$-tests. All data are reported as means and $95 \%$ confidence intervals unless otherwise stated. A probability value of 0.05 or less was considered significant.

\section{Results}

Compliance with the fish oil and olive oil capsules was confirmed with bottle counts which suggested full consumption of the prescribed regimens. Assessment of platelet lipid fractions demonstrated the incorporation of both eicosapentaenoic acid and docosahexaenoic acid at the expense of arachidonic acid (Table 1). The eicosapentaenoic acid/arachidonic acid ratio increased from 0.05 (confidence interval (CI): 0.04 to 0.06$)$ at baseline to $0.15(\mathrm{CI}$ : 0.13 to 0.17$) p<0.001$ with fish oil supplementation. Similar increases occurred in the docosahexaenoic acid/arachidonic acid ratio with fish oil therapy confirming significant consumption of the oils during the study period.

The haemodynamic and metabolic parameters recorded at the outset of the baseline study and after 6 weeks fish oil and olive oil administration are summarized in Table 2. No significant changes occurred in mean arterial pressure, heart rate, basal forearm blood flow or basal forearm vascular resistance with fish oil or olive oil supplementation when compared to baseline values. The mean fasting blood glucose increased from 
Table 2. Haemodynamic and metabolic parameters at baseline and after 6 weeks fish oil and olive oil supplementation

\begin{tabular}{|c|c|c|c|}
\hline & Baseline & Fish oil & Olive oil \\
\hline Mean arterial pressure $(\mathrm{mm} \mathrm{Hg})$ & $83(78$ to 88$)$ & $79(75$ to 83$)$ & $82(76$ to 88$)$ \\
\hline Heart rate (beats/min) & $71(60$ to 82$)$ & $70(60$ to 80$)$ & $71(61$ to 81$)$ \\
\hline Forearm vascular resistance (units) & $28(20$ to 36$)$ & $25(18$ to 32$)$ & $24(20$ to 28$)$ \\
\hline Fasting glucose $(\mathrm{mmol} / \mathrm{l})$ & $10.2(8.9$ to 11.4$)$ & $11.4(9.7$ to 13.3$)$ & $11.0(9.3$ to 12.7$)$ \\
\hline Total cholesterol $(\mathrm{mmol} / 1)^{\mathrm{a}}$ & $5.3(4.9$ to 5.7$)$ & $5.3(4.9$ to 5.7$)$ & $5.3(4.9$ to 5.7$)$ \\
\hline Total triglyceride $(\mathrm{mmol} / \mathrm{l})^{\mathrm{b}}$ & $1.8(1.4$ to 2.2$)$ & $1.4(1.1$ to 1.8$)$ & $1.6(1.4$ to 1.9$)$ \\
\hline
\end{tabular}

${ }^{\mathrm{a}} \mathrm{mmol} / \mathrm{l}=\mathrm{mg} / \mathrm{dl} \times 0.026 ;{ }^{\mathrm{b}} \mathrm{mmol} / \mathrm{l}=\mathrm{mg} / \mathrm{dl} \times 0.0114$. Values expressed are means and $95 \%$ confidence intervals

baseline with fish oil administration though the change just failed to reach statistical significance $(p=0.06)$. A reduction in fasting triglyceride levels occurred with fish oil therapy when compared with baseline values though the trend was not significant ( $p=0.07$ ) largely due to the paradoxical increase in fasting triglyceride levels that occurred in some patients due to fish oil administration.

The incremental intra-arterial infusions of acetylcholine produced no changes in systemic blood pressure, heart rate or altered forearm blood flow in the noninfused arm in the diabetic subjects at baseline or after either intervention.

Figure 1 summarises the mean changes in forearm blood flow in response to the intra-arterial infusion of acetylcholine in the diabetic subjects during the baseline study and after 6 weeks olive oil and fish oil administration. The infusions of acetylcholine increased forearm blood flow from basal values during each separate study, although the magnitude of change after fish oil administration was significantly greater for each dose of acetylcholine infused when compared to changes recorded during the baseline study and after olive oil administration $(p<0.01$ for each dose). The mean increase in forearm blood flow for the four doses of acetylcholine with fish oil was 5.3 (CI: 4.0 to

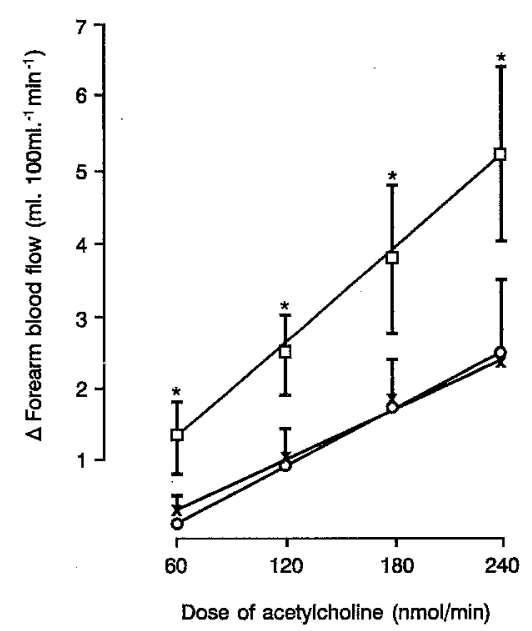

Fig. 1. Plots of mean changes and $95 \%$ confidence intervals of the changes in forearm blood flow to the intra-brachial infusions of the four doses of acetylcholine $(60,120,180$ and $240 \mathrm{nmol} / \mathrm{min})$ in the 23 diabetic subjects during the baseline studies $(O-O)$ and after dietary supplementation with olive oil $(x-x)$ and fish oil $(\square-\square)$ for 6 weeks. $* p<0.01$ for each dose
6.6) $\mathrm{ml} \cdot 100 \mathrm{ml}^{-1} \cdot \mathrm{min}^{-1}$. This compared with a mean increase in forearm blood flow during the baseline study of 2.5 (CI: 1.3 to 3.7 ) $\mathrm{ml} \cdot 100 \mathrm{ml}^{-1} \cdot \mathrm{min}^{-1}$ and after olive oil supplementation of 2.2 (CI:1.1 to 3.3 ) $\mathrm{ml} \cdot 100 \mathrm{ml}^{-1} \cdot \mathrm{min}^{-1}$. No differences were found between the mean increases in forearm blood flow to acetylcholine during the baseline study and after olive oil therapy.

Figure 2 illustrates the changes in forearm blood flow to the acetylcholine infusions in the diabetic subjects after dietary fish oil supplementation. Initially the four doses of acetylcholine were administered to produce the maximal stimulated flow to this agent and the natural decline in flow was recorded until basal conditions were re-established. The four doses of acetylcholine were then reinfused to give reproducible vasodilation. L-NMMA at a dose of $2 \mu \mathrm{mol} / \mathrm{min}$ was then infused for $5 \mathrm{~min}$ to inhibit that component of the increased blood flow to acetylcholine attributable to NO release from the endothelium. L-NMMA produced an immediate decline in blood flow and this change in forearm blood flow differed significantly from the natural decline in flow recorded after the initial acetylcholine infusions when compared at the same time points $(p<0.01)$.

L-NMMA was infused in each diabetic subject during the baseline studies and after fish oil and olive oil administration at $2 \mu \mathrm{mol} / \mathrm{min}$ for $5 \mathrm{~min}$ to assess the effect of the arginine analogue on basal blood flow (Table 3). At this dosage, a modest reduction in basal blood flow occurred in the diabetic subjects when ingesting the fish oil supplements. This trend just failed to reach statistical significance when compared with the responses recorded at baseline and after olive oil supplementation (overall MANOVA $p=0.08$ ). No differences in the responses to the incremental infusions of glyceryl trinitrate were found with either intervention when compared to changes at baseline. The mean increase in forearm blood flow recorded during the baseline study was 0.6 (CI: 0.3 to $0.9) \mathrm{ml} \cdot 100 \mathrm{ml}^{-1} \cdot \mathrm{min}^{-1}$ and after olive oil and fish oil were 0.7 (CI: 0.2 to 1.2 ) $\mathrm{ml} \cdot 100 \mathrm{ml}^{-1} \cdot \mathrm{min}^{-1}$ and 0.8 (CI: 0.4 to 1.2$) \mathrm{ml} \cdot 100 \mathrm{ml}^{-1} \cdot \mathrm{min}^{-1}$ respectively.

\section{Discussion}

Dietary supplementation with fish oil markedly improved endothelium-dependent vasodilation to acetylcholine 


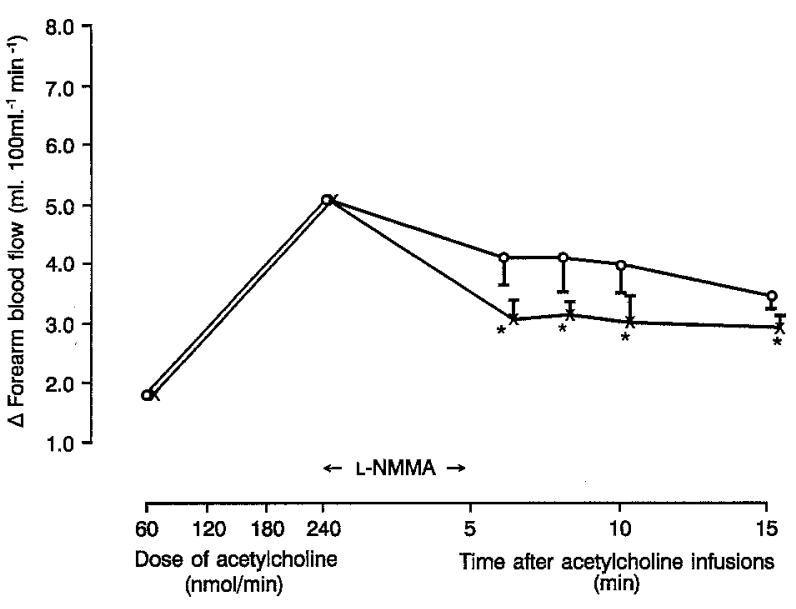

Fig. 2. Plots of mean changes and $95 \%$ confidence intervals of the changes of the decline in forearm blood flow in the 23 diabetic patients during fish oil ingestion from the maximal stimulated flow $(\mathrm{O}-\mathrm{O})$ to the incremental intra-brachial infusions of acetylcholine, $60,120,180$ and $240 \mathrm{nmol} / \mathrm{min}$. When basal conditions were re-established the four doses of acetylcholine were re-infused to give reproducible vasodilation. $\mathrm{N}^{\mathrm{G}}$-monomethyl-L-arginine (L-NMMA) was infused at $2 \mu \mathrm{mol} / \mathrm{min}$ to inhibit that component of the increased blood flow to acetylcholine attributable to nitric oxide release from the endothelium $(x-x)$. At comparable time points L-NMMA produced a significantly greater decline in forearm blood flow compared with the uninhibited decline in flow to the acetylcholine infusions. $p<0.01$ at each time point

when compared with responses recorded at baseline in the forearm vasculature of patients with Type 2 diabetes. By contrast, no changes occurred in the vasodilator responses to acetylcholine after olive oil supplementation. Endothelium-independent responses to glyceryl trinitrate were unaffected by either fish oil or olive oil administration.

Prior studies have shown that omega-3 fatty acids improve stimulated NO release from atherosclerotic endothelium in response to various pharmacological agents [11]. The mechanisms involved remain obscure but may relate to changes in receptor-effector coupling or to alterations in cell membrane fluidity [12]. We employed acetylcholine to stimulate NO release and L-NMMA, a stereospecific inhibitor of NO production or release, to assess endothelium-dependent vascular responses [16]. Forearm vasodilation to acetylcholine may also be influenced through inhibition of noradrenaline release from sympathetic nerve endings or by stimulating vascular

Table 3. Change in forearm blood flow after 1 and $5 \mathrm{~min}$ to the intrabrachial infusion of $\mathrm{N}^{\mathrm{G}}$-monomethyl-L-arginine at baseline and after 6 weeks fish oil and olive oil supplementation

\begin{tabular}{lll}
\hline & \multicolumn{2}{l}{ Change in forearm blood flow } \\
\cline { 2 - 3 } & $1 \mathrm{~min}$ & $5 \mathrm{~min}$ \\
\hline Baseline & $+0.1(-0.3$ to +0.4$)$ & $+0.3(-0.2$ to 0.8$)$ \\
Fish oil & $-0.6(-0.9$ to -0.3$)$ & $-0.4(-0.8$ to 0.0$)$ \\
Olive oil & $0 \quad(-0.2$ to +0.2$)$ & $0 \quad(-0.4$ to +0.4$)$ \\
\hline
\end{tabular}

Units are $\mathrm{ml} \cdot 100 \mathrm{ml}^{-1} \cdot \mathrm{min}^{-1}$. Values expressed are mean change and $95 \%$ confidence intervals of the change. $p=0.08$ on comparing overall responses after fish oil with those recorded at baseline and after olive oil administration prostacyclin production. However, prior studies in patients with hypertension $[17,18]$ suggest that changes in catecholamine release or increases in vasodilating prostaglandins to the intra-brachial infusion of acetylcholine play little part in influencing forearm blood flow. We cannot exclude a possible contribution of vasodilator prostaglandins in improving the forearm blood flow responses to acetylcholine in this study as prostanoid metabolism was influenced by the prescription of the fish oil supplements to the diabetic subjects.

Our data lend support to increased receptor stimulated release of $\mathrm{NO}$ as an important component of the improved vasodilator response in diabetic patients ingesting fish oils. The increased relaxation to infused acetylcholine coupled with the marked decline in stimulated forearm blood flow to acetylcholine produced by L-NMMA, compared with the uninhibited decline in flow to the acetylcholine infusions, is consistent with enhanced NO release augmenting the vasodilator responses associated with fish oil administration. A modest reduction in basal blood flow was observed after the intra-brachial infusion of L-NMMA in the diabetic patients during fish oil supplementation that was not observed during the baseline study or after olive oil administration. This may indicate enhanced basal release of NO by the endothelium although this trend just failed to reach significance at the dose of L-NMMA infused and with the dose of fish oil prescribed.

In addition to promoting receptor-mediated vasodilation fish oils may alter vascular reactivity through a direct effect on smooth muscle cells or indirectly by altering the production of substances by other cells that affect endothelial cell function. Omega-3 fatty acids can inhibit leucocyte/endothelium interactions [19] possibly resulting in fewer reactive oxygen species that can inactivate $\mathrm{NO}[8$, 20]. By inhibiting the release of platelet and endotheliumderived vasoconstrictor factors, fish oil therapy could augment vascular relaxations and favour a more vasodilated state. Finally, it has been suggested that omega-3 fatty acids influence the sensitivity of vascular smooth muscle cells promoting improved relaxations to pharmacological agents $[11,21]$. With the doses of fish oils prescribed in this study, no differences were found in the dose-response curves to glyceryl trinitrate when baseline responses were compared with responses recorded after fish oil and olive oil interventions. These findings appear to exclude a non-specific change in vascular smooth muscle sensitivity as being responsible for the improved relaxations to acetylcholine recorded after fish oil administration.

Impaired vasodilator responses to acetylcholine and glyceryl trinitrate have been described in experimental models of diabetes [22]. We have previously reported impaired forearm vasodilator responses to the intra-brachial infusion of these agents in patients with Type 2 diabetes compared with a group of age- and sex-matched control subjects [15]. Fish oil therapy improved forearm vasodilator responses in diabetic subjects so that the dose-response curves to the acetylcholine infusions overlapped those previously recorded in healthy control subjects, without influencing the impaired responses to glyceryl 
trinitrate. These data may provide indirect evidence for impaired biotransformation of glyceryl trinitrate to $\mathrm{NO}$ in the diabetic patients. NO whether produced in the endothelium by the action of acetylcholine on muscarinic receptors, or after the biotransformation of glyceryl trinitrate in the smooth muscle cell, combines with guanylate cyclase in vascular smooth muscle to stimulate cyclic GMP and produce ultimate vasodilation [23]. The biotransformation of glyceryl trinitrate to NO requires the presence of intracellular sulphydryl groups. Depletion or oxidation of intracellular sulphydryl groups in vascular smooth muscle would impair the biotransformation process and render the vasculature tolerant to the drug [24], without however altering the sensitivity to endogenously produced NO $[25,26]$. It is recognised that cellular levels of sulphydryl donors and serum levels of primary antioxidants are decreased in diabetes [27, 28]. Thus, the increased oxidative stress associated with diabetes may promote oxidation or depletion of intracellular sulphydryl donors in diabetic subjects and impair the vasodilator responses to glyceryl trinitrate, without altering the smooth muscle response to endothelium-derived NO.

Deleterious effects on glucose and fatty acid regulation have been reported in diabetic patients ingesting fish oils $[4,29]$. We observed a minor increase in fasting glucose levels with no change in total cholesterol and a non-sig. nificant decrease in fasting triglyceride levels to fish oil administration in this short-term study. These results further emphasize that the vascular effects of omega- 3 fatty acids can be dissociated from their lipid lowering actions. Chronic endothelial injury associated with diabetes facilitates platelet aggregation and the release of platelet products that may cause vasospasm and thrombosis. Fish oils may curtail these events not only through a direct effect on platelets but also by augmenting the release of endothelium-derived $\mathrm{NO}$ and possibly vasodilator prostaglandins [30]. As impaired NO release from the endothelium has been implicated in the very earliest steps of atherogenesis [31], omega-3 fatty acids could potentially retard a process in diabetic subjects that does not appear to be influenced by interventions that have concentrated on improving blood glucose control alone.

If a single dietary change could provide long-term protection from the micro- and macrovascular complications associated with diabetes, it would have considerable therapeutic potential. While the results of this study are encouraging, long-term trials under defined conditions of metabolic control and diet are required to confirm the safety and efficacy of fish oil administration before they can be recommended as an adjunct to traditional diabetic therapy.

Acknowledgements. This work was supported by a grant from the British Diabetic Association. Dr. Brennan is a Research Fellow supported by the British Diabetic Association.

\section{References}

1. Panzram G (1987) Mortality and survival in type 2 (non-insulindependent) diabetes mellitus. Diabetologia 30: 123-131
2. Ruderman NB, Haudenschild C (1984) Diabetes as an atherogenic factor. Prog Cardiovasc Dis 26: 373-412

3. DCTT Research Group (1988) Are continuing studies of metabolic control and microvascular complications in insulin-dependent diabetes mellitus justified? The Diabetes Control and Complications Trial. N Eng1 J Med 318: 246-250

4. Editorial. Fish oils and diabetic microvascular disease (1990) Lancet 335: 508-509

5. Kromhout D, Bosschieter EB, de Lezenne Coulander C (1985) The inverse relation between fish consumption and 20-year mortality from coronary heart disease. N Engl J Med 312: 10251029

6. Burr ML, Fehily AM, Gilbert JF et al. (1989) Effects of changes in fat, fish, and fibre intakes on death and myocardial infarction: diet and reinfarction trial (DART). Lancet II: 757-761

7. Jensen T, Stender S, Goldstein K, Holmer G, Deckert T (1989) Partial normalisation by dietary cod-liver oil of increased microvascular albumin leakage in patients with insulin-dependent diabetes and albuminuria. N Engl I Med 321:1572-1577

8. Leaf A (1990) Cardiovascular effects of fish oils. Beyond the platelet. Circulation 82: 624-628

9. Shimokawa H, Lam JYT, Chesebro JH, Bowie EJW, Vanhoutte PM (1987) Effects of dietary supplementation with cod-liver oil on endothelium-dependent responses in porcine coronary arteries. Circulation 76: 898-905

10. Vekshtein VI, Yeung AC, Vita JA et al. (1989) Fish oil improves endothelium-dependent relaxations in patients with coronary artery disease. Circulation 80: [Suppl 2]

11. Shimokawa H, Vanhoutte PM (1988) Dietary cod-liver oil improves endothelium-dependent responses in hypercholesterolemic and atherosclerotic porcine coronary arteries. Circulation 78: 1421-1430

12. Boulanger C, Schini VB, Hendrickson H, Vanhoutte PM (1990) Chronic exposure of cultured endothelial cells to eicosapentaenic acid potentiates the release of endothelium-derived relaxing factor(s). Br J Pharmacol 99: 176-180

13. Palmer RMJ, Ferrige AG, Moncada S (1987) Nitric oxide release accounts for the biological activity of endothelium-derived relaxing factor. Nature 327: 524-526

14. Myers PR, Minor RL Jr, Bates JW, Harrison DG (1990) Vasorelaxant properties of endothelium derived relaxing factor more closely tesemble S-nitrocysteine than nitric oxide. Nature 345: 161-163

15. McVeigh GE, Brennan GM, Johnston GD et al. (1992) Impaired endothelium-dependent and independent responses in type 2 (non-insulin dependent) diabetes mellitus. Diabetologia 35:771776

16. Johns RA, Peach MJ, Linden J, Tichotsky A (1990) NG monomethyl-L-arginine inhibits endothelium derived relaxing factorstimulated cyclic GMP accumulation in cocultures of endothelial and vascular smooth muscle cells by an action specific to the endothelial cell. Circ Res 67: 979-985

17. Panza JA, Quyyumi AA, Brush JE Jr, Epstein SE (1990) Abnormal endothelium-dependent vascular relaxation in patients with essential hypertension. N Engl J Med 323:22-27

18. Linder L, Kiowski W, Buhler FR, Luscher TF (1990) Indirect evidence for release of endothelium-derived relaxing factor in human forearm circulation in vivo. Blunted response in essential hypertension. Circulation 81: 1762-1767

19. Lehr H-A, Hubner C, Finckh B et al. (1991) Dietary fish oil reduces leucocyte/endothelium interaction following systemic administration of oxidatively modified low density lipoprotein. Circulation 84: 1725-1731

20. Gryglewski RJ, Palmer RMJ, Moncada S (1986) Superoxide anion is involved in the breakdown of endothelium-derived relaxing factor. Nature 320: 454-456

21. Maws CD, Leaf AL, Varadarajan GS et al. (1991) Effects of dietary W3 fatty acids on vascular contractility in preanoxic and postanoxic aortic rings. Circulation 84: 1393-1401

22. Bucala R, Tracey KS, Cerami A (1991) Advanced glycosylation products quench nitric oxide and mediate defective endothe- 
lium-dependent vasodilation in experimental diabetes. J Clin Invest $87: 432-438$

23. Ignarro LJ (1989) Biological actions and properties of endothelium-derived nitric oxide formed and released from artery and vein. Circ Res 65: 1-21

24. Ignarro LJ, Lippton H, Edwards JC et al. (1981) Mechanism of vascular smooth muscle relaxation by organic nitrates, nitrites, nitroprusside and nitric oxide: evidence for the involvement of s-nitrosothiols as active intermediates. J Pharmacol Exp Ther 218: 739-749

25. Elkayamu A (1991) Tolerance to organic nitrates: evidence, mechanisms, clinical relevance, and strategies for prevention. Ann Int Med 114: 667-677

26. Forster B, Woditsch I, Schroder H, Schror K (1991) Reduced nitric oxide release causes nitrate tolerance in the intact coronary circulation. J Cardiovasc Pharmacol 17: 867-872

27. Chari SN, Nath N, Rathi AB (1984) Glutathione and its redox system in diabetic polymorphonuclear leucocytes. Am J Med Sci 287: 14-15

28. Hunt JV, Smith CCT, Wolff SP (1990) Autoxidative glycosylation and possible involvement of peroxides and free radicals in LDL modification by glucose. Diabetes 39: 1420-1424
29. Borkman M, Chisholm DJ, Furler SM et al. (1989) Effects of fish oil supplementation on glucose and lipid metabolism in NIDDM. Diabetes 38: 1314-1319

30. Force T, Milanc R, Hibberd P et al. (1991) Aspirin-induced decline in prostacyclin production in patients with coronary artery disease is due to decreased endoperoxide shift. Circulation 84 : 2286-2293

31. Cohen RA, Zitnay KM, Haudenschild CL, Cunningham LD (1988) Loss of selective endothelial cell vasoactive functions caused by hypercholesterolemia in pig coronary arteries. Circ Res 63: 903-910

Received: 22 June 1992

and in revised form: 25 August 1992

Dr. G.E.McVeigh

Department of Therapeutics and Pharmacology

The Queen's University of Belfast

Whitla Medical Building

97 Lisburn Road

Belfast BT9 7BL

Northern Ireland 